\section{Successful endoscopic extraction of a double uncovered expandable metal stent}

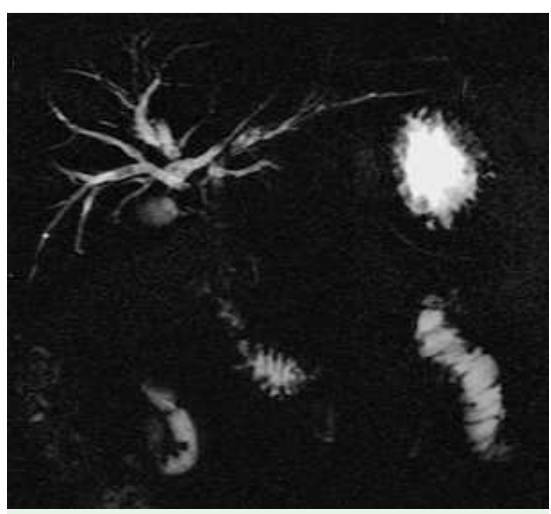

Fig. 1 Magnetic resonance (MR) cholangiography showing obstruction of both Wallstents completely embedded in the bile duct walls.

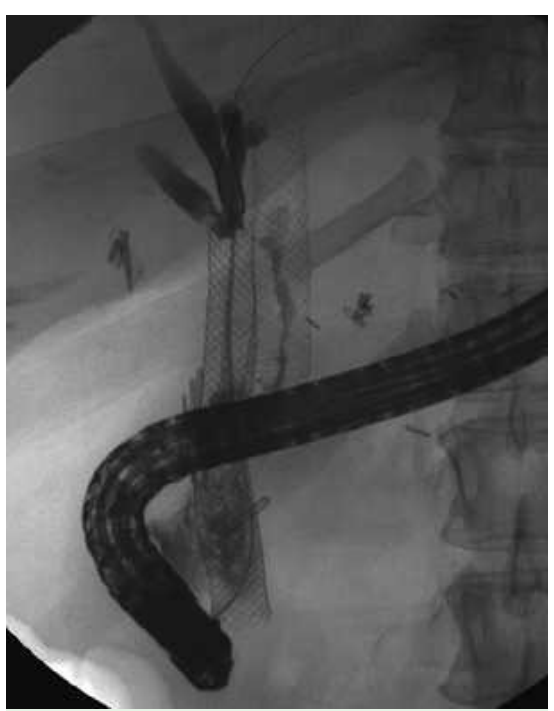

Fig. 2 Endoscopic retrograde cholangiopancreatography (ERCP) image confirming obstruction of the Wallstents.

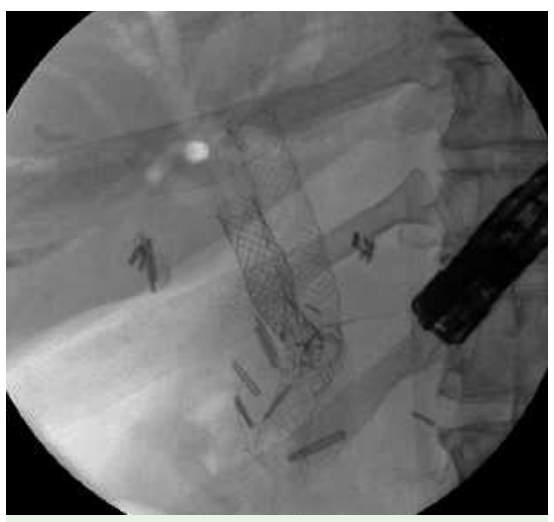

Fig. 3 Wire-by-wire extraction of the first stent with rat-tooth forceps.

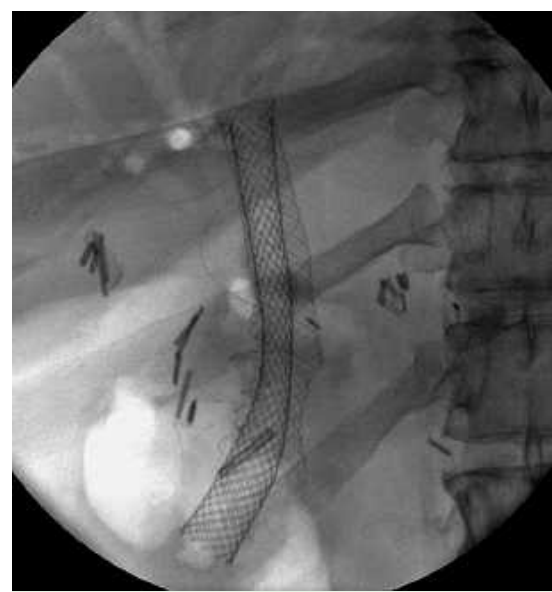

Fig. 4 Insertion of a covered metal stent into the second embedded stent to decrease intraluminal endothelial hyperplasia.

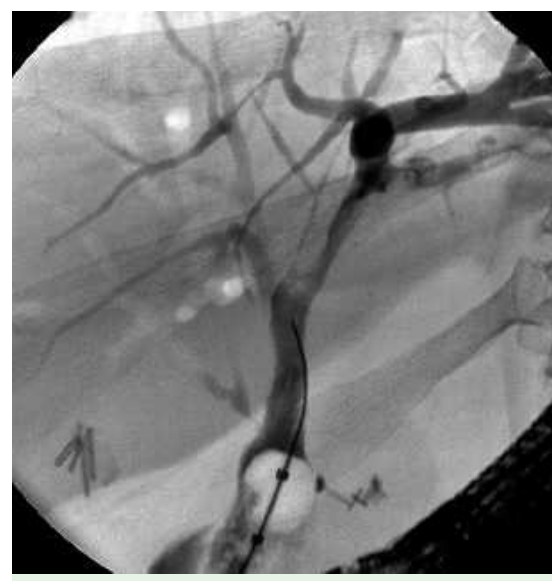

Fig. 5 ERCP image showing complete extraction without bile leakage or strictures.

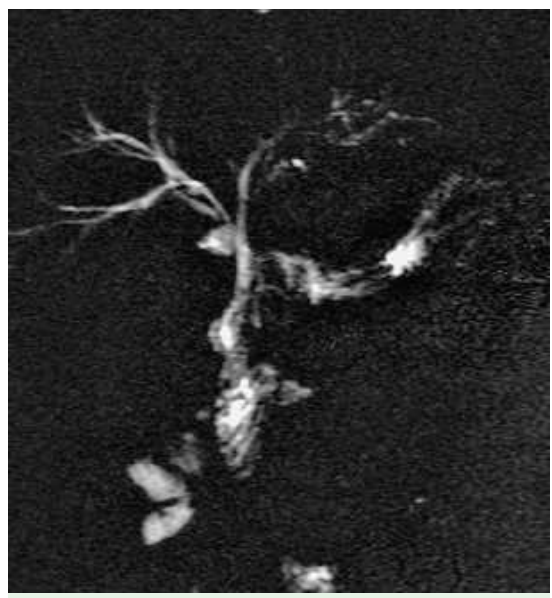

Fig. 6 MR cholangiography at 6-month follow-up showing good clearance of the extrahepatic and intrahepatic bile ducts.
Extraction of covered metal stents has been previously described [1-5]. We report the case of a young patient in whom we removed two uncovered Wallstents that had been placed in the left and right liver lobes because of an unresectable Klatskin tumor 6 years earlier.

The 36-year-old woman presented with icterus and gallbladder stones in 2002. Extensive work-up including CT, MRI, endoscopic ultrasonography, positron emission tomography, and laparotomy with histological study of the lesion concluded in the diagnosis of a Klatskin tumor invading the inferior vena cava with metastases in the liver. The patient underwent palliative treatment with placement of two Wallstents and gemcitabine chemotherapy for 1 year.

In 2007 she presented with recurrent cholangitis and obstruction of both stents ( Fig. 1), which necessitated several sessions of endoscopic retrograde cholangiography to extract stones ( $\bullet$ Fig. 2). Surprisingly, biliary brush specimens lacked any signs of malignancy and therefore put in question the diagnosis of malignancy in favor of one of inflammatory pseudotumor.

After consideration of total surgical common bile duct and stent excision as opposed to endoscopic retrieval, we decided for an endoscopic approach. Extraction was performed in two sessions (taking 1.5 hours and 2 hours respectively). The chosen approach was a wire-by-wire extraction after an unsuccessful attempt to grasp the stents in a snare. Multiple devices were used: endoscopic rat-tooth and crocodile forceps ( $\bullet$ Fig. 3), snares, and several Dormia baskets, the most useful being the rat-tooth forceps.

Prior to the extraction of the second Wallstent, which was completely embedded in the bile ducts, a covered Wallstent was inserted into the preexisting uncovered stent to decrease the endoluminal hyperplasia ( $\bullet$ Fig. 4). The covered stent was easily retrieved with a monofilament mucosectomy snare, and wire-by-wire extraction of the last stent was then successful ( Fig. 5). No complications were reported, and control MRI at 6-month follow-up showed good clearance of the bile duct with no intrahepatic strictures (๑ Fig. 6).

Endoscopy_UCTN_Code_TTT_1AR_2AZ 
M. Lahlal ${ }^{1}$, J.-F. Gigot ${ }^{2}$, L. Annet ${ }^{3}$, P. H. Deprez

1 Department of Gastroenterology, Cliniques Universitaires Saint-Luc, Université Catholique de Louvain, Brussels, Belgium

2 Department of Digestive Surgery, Cliniques Universitaires Saint-Luc, Université Catholique de Louvain, Brussels, Belgium

${ }^{3}$ Department of Radiology, Cliniques Universitaires Saint-Luc, Université Catholique de Louvain, Brussels, Belgium

"M. Lahlal is a student at the Medizinische Universität Wien, Vienna, Austria.

\section{References}

1 Kahaleh M, Tokar J, Le T et al. Removal of self-expandable metallic Wallstents. Gastrointest Endosc 2004; 60: 640-644

2 Egan LJ, Baron TH. Endoscopic removal of an embedded biliary Wallstent by piecemeal extraction. Endoscopy 2000; 32: $492-494$

3 Levy MJ, Wiersema MJ. Endoscopic removal of a biliary Wallstent with a suture-cutting device in a patient with primary pancreatic lymphoma. Endoscopy 2002; 34: 835-837

4 Shin HP, Kim MH, Jung SW et al. Endoscopic removal of biliary self-expandable metallic stents: a prospective study. Endoscopy 2006; 38: 1250-1255

5 Larghi A, Waxman I. Endoscopic ultrasoundguided rescue of an uncovered self-expanding metallic stent causing biliary obstruction. Endoscopy 2006; 38: 857
Bibliography

DOI 10.1055/s-2008-1077770

Endoscopy 2009; 41: E98 - E99

(c) Georg Thieme Verlag KG Stuttgart · New York . ISSN 0013-726X

\section{Corresponding author}

\section{P. H. Deprez, MD, PhD}

Department of Gastroenterology

Cliniques Universitaires Saint-Luc

Avenue Hippocrate, 10

1200 Brussels

Belgium

Fax: +32-2-7648927

pdeprez@uclouvain.be 